\title{
American Neurogastroenterology and Motility Society consensus statement on intraluminal measurement of gastrointestinal and colonic motility in clinical practice
}

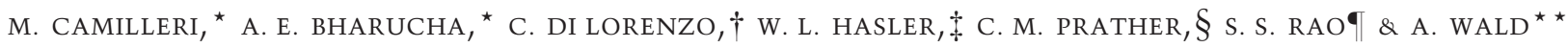 \\ ${ }^{\star}$ CENTER Program, Mayo Clinic, Rochester, MN, USA \\ $\dagger$ Department of Pediatrics, The Ohio State University, Columbus, OH, USA \\ †Department of Gastroenterology, University of Michigan, Ann Arbor, MI, USA \\ $\S$ Department of Gastroenterology, St Louis University, St Louis, MO, USA \\ -Division of Gastroenterology, Carver College of Medicine, University of Iowa, Iowa City, IA, USA \\ * Section of Gastroenterology \& Hepatology, School of Medicine and Public Health, University of Wisconsin, Madison, WI, USA
}

\begin{abstract}
Tests of gastric, small intestinal and colonic motor function provide relevant physiological information and are useful for diagnosing and guiding the management of dysmotilities. Intraluminal pressure measurements may include concurrent measurements of transit or intraluminal $\mathrm{pH}$. A consensus statement was developed and based on reports in the literature, experience of the authors, and discussions conducted under the auspices of the American Neurogastroenterology and Motility Society in 2008. The article reviews the indications, methods, performance characteristics, and clinical utility of intraluminal measurements of pressure activity and tone in the stomach, small bowel and colon in humans. Gastric and small bowel motor function can be measured by intraluminal manometry, which may identify patterns suggestive of myopathy, neuropathy, or obstruction. Manometry may be most helpful when it is normal. Combined wireless pressure and $\mathrm{pH}$ capsules provide information on the amplitude of contractions as they traverse the stomach and small intestine. In the colon, manometry assesses colonic phasic pressure activity while a barostat assesses tone, compliance, and phasic
\end{abstract}

Address for correspondence

Michael Camilleri MD, Mayo Clinic, Charlton 8-110, 200

First St. S.W., Rochester, MN 55905, USA.

Tel: +1 507266 2305; fax: +1 507538 5820;

e-mail: camilleri.michael@mayo.edu

Received: 27 August 2008

Accepted for publication: 10 October 2008 pressure activity. The utility of colonic pressure measurements by a single sensor in wireless pressure/pH capsules is not established. In children with intractable constipation, colonic phasic pressure measurements can identify patterns suggestive of neuropathy and predict success of antegrade enemas via cecostomy. In adults, these assessments may be used to document severe motor dysfunction (colonic inertia) prior to colectomy. Thus, intraluminal pressure measurements may contribute to the management of patients with disorders of gastrointestinal and colonic motility.

Keywords capsule, compliance, manometry, pH, pressure, tone.

\section{INTRODUCTION}

Assessments of gastrointestinal (GI) and colonic motility by intraluminal techniques provide an understanding of GI physiology and the pathophysiology of motility disorders. They may also facilitate evaluation of patients with suspected disorders of GI or colonic motility. The American Neurogastroenterology and Motility Society selected a group of clinician-investigators to develop a consensus statement based on reports in the literature, experience of the authors, and discussions on tests used for intraluminal pressure measurements of different regions of the stomach, small intestine and colon. Manometry can be performed either in a laboratory setting (stationary) or 
using ambulatory systems, with the patient outside the laboratory. On the other hand, the measurement of colonic tone and compliance requires a laboratorybased study with a barostat. The scope of the article is not to provide a technical manual on how to perform the studies; rather it explores the evidence supporting the utility of such investigations in clinical practice.

The material used to compile this report included literature reviews and discussions in closed fora among the authors under the auspices of the American Neurogastroenterology and Motility Society in 2008. The reader should assume that, unless a statement is referenced, it represents the consensus opinion of the authors. The perspectives reflect predominantly the conduct of such tests in the United States. There are regional variations in applications of the tests in different health systems or countries; however, the indications, endpoints, strengths and pitfalls are relevant to practice everywhere. Information on coding and billing of procedures is available at http://www. motilitysociety.org/.

\section{Intraluminal gastroduodenojejunal phasic pressure recordings (Manometry)}

Introduction Technical details regarding preparation, catheters and other equipment, intubation techniques, test meals, and a comparison between stationary and ambulatory (including $24 \mathrm{~h}$ ) studies are detailed elsewhere. ${ }^{1}$

Clinical indications The main indications for gastroduodenojejunal manometry appear in Table 1.

Table 1 Indications for gastroduodenojejunal manometry

1 Clarify the diagnosis in patients with unexplained nausea, vomiting or symptoms suggestive of upper GI dysmotility

2 Differentiate between neuropathic vs myopathic gastric or small bowel dysfunction

3 Identify generalized dysmotility in patients with colonic dysmotility (e.g. chronic constipation), particularly prior to subtotal colectomy

4 Confirm diagnosis in suspected chronic intestinal pseudoobstruction syndromes when the diagnosis is unclear on clinical or radiological grounds

5 Assess for possible mechanical obstruction when clinical features suggest, but radiological studies do not reveal, obstruction

6 Determine which organs need to be transplanted (isolated vs multi-visceral transplantation) in patients with chronic intestinal pseudo-obstruction being considered for intestinal transplantation

7 Confirm a diagnosis of rumination syndrome
Outcomes and endpoints of test There is consensus in the literature that manometry can, with reasonable confidence, distinguish normal from abnormal activity and also characterize mechanisms, as detailed below. The need for and utility of gastroduodenal manometry are strongly dependent on clinical circumstances. Thus, manometric data are not essential for patient management when there is a known underlying cause of dysmotility and particularly if similar information can be obtained non-invasively, such as by measuring transit.

Normal motility includes:

1 At least one migrating motor complex (MMC) per $24 \mathrm{h.}^{2}$

2 Conversion to the fed pattern without return of MMC for at least $2 \mathrm{~h}$ after a $400-\mathrm{kcal}$ meal. ${ }^{3}$

3 Distal antral contractility (postprandial motility index per $2 \mathrm{~h}>13.67) .{ }^{4}$

4 Antral contractions $>40 \mathrm{mmHg}$ and small intestinal contractions $>20 \mathrm{mmHg}{ }^{5}$

5 Absence of abnormal patterns described below. As longer recordings are subjected to computer analysis, it is possible that other quantitative indices may better define normality.

Mechanical obstruction of the small intestine may be diagnosed by manometry even when undetected radiologically. Two manometric patterns of obstruction have been reported: ${ }^{6}$ postprandial clustered contractions (>30-min duration) separated by quiescence or simultaneous prolonged $(>8 \mathrm{~s})$ or summated contractions.

Myopathic disorders (e.g. scleroderma, amyloidosis, hollow visceral myopathy) are characterized by lowamplitude contractions $(<20 \mathrm{mmHg})$ at affected sites. 5,7

Antral hypomotility or reduced motility index of postprandial distal antral contractions is significantly correlated with the impaired gastric emptying of solids in disease states and pharmacological models of gastroparesis. ${ }^{4,8}$ Patients with scleroderma with gastric involvement have an average antral amplitude of $<40 \mathrm{mmHg}$. ${ }^{9}$ While nutritional trials (e.g. gastric feeding) are worthwhile, experience suggests that manometric findings (e.g. antral amplitude) are useful for providing dietary recommendations and identifying site of feeding (e.g. jejunum).

After vagotomy, duodenojejunal MMCs occur more frequently ( $>3$ over $3 \mathrm{~h}$ ) during the fasting period when patients are awake; the antral phase III of the MMC is often absent, ${ }^{10,11}$ and there is postprandial antral hypomotility and a rapid return of MMC activity (within $2 \mathrm{~h}$ ) after a $>400$-kcal meal. ${ }^{10}$ Alternative noninvasive approaches can be used to assess vagal integ- 
rity, such as the plasma pancreatic polypeptide response to modified sham feeding. ${ }^{12}$

'Neuropathic' disorders have been associated with antral hypomotility, abnormal propagation of the MMC, hypercontractility in the duodenojejunum (bursts and sustained uncoordinated pressure activity), and failure of the fed response. Studies that compared manometric and histological findings are weak, as they are based on single reports, ${ }^{13}$ incomplete analyses of either manometric or histological features, ${ }^{14,15}$ lack of normal controls and equivocal histological findings. ${ }^{16}$ Therefore, these manometric criteria for neuropathic disorders are predominantly based on a largely clinical gastroduodenal manometry database that identified manometric patterns in patients with different neuropathic diseases, including diabetes ${ }^{17}$ other autonomic neuropathies, ${ }^{18}$ vagotomy, ${ }^{10}$ effects of central nervous system lesions including brainstem tumours, ${ }^{19}$ and chronic intestinal pseudo-obstruction in the absence of extrinsic neurological disorder. ${ }^{20-22}$

Rumination syndrome is typically characterized by postprandial, artifactual increase in intra-abdominal pressure at all levels of the upper gut. ${ }^{23}$ A careful clinical history usually suffices for diagnosing rumination in adults and adolescents, ${ }^{24}$ especially if gastric emptying is normal and there is no gastro-oesophageal reflux in the supine position. Antroduodenojejunal manometry can confirm the diagnosis when necessary. ${ }^{23-25}$

Confounding issues Interpretation of intestinal manometry may be confounded by:

1 Artefacts caused by cough, movement, or straining which result in simultaneous pressure activity recorded by multiple sensors. Contractions in dilated intestinal segments may also cause identical pressure waves recorded by multiple sensors (i.e. a common cavity phenomenon); these may be misinterpreted as simultaneous contractions arising from the different sites.

2 There is a limited motor repertoire of gut motility that can be measured by manometry; e.g. frequency and propagation of MMCs, contractile amplitude at different levels and postprandial antral hypomotility. Several dysmotility syndromes may share common manometric features: diabetes mellitus, gastric surgery, chronic intestinal pseudo-obstruction and 'idiopathic' dysmotility exhibit manometric features of autonomic denervation (references provided above). Other disorders may exhibit, at different stages in their natural history, either combinations of autonomic and enteric neuropathy (e.g. Parkinsonism plus or Shy-Drager syndrome) or enteric neuropathy and myopathy (e.g. amyloidosis and scleroderma).
3 Abnormal motor patterns do not necessarily demonstrate the cause of the patient's symptoms, and may be secondary to a disease outside the upper gut (e.g. anorexia nervosa ${ }^{26,27}$ or constipation ${ }^{28}$ ) and may be rapidly reversible with correction of the associated disease, e.g. restoration of normal eating habits. ${ }^{29}$

4 Displacement of the motility catheter, e.g. out of the distal antrum, prevents optimal measurement.

New methods that utilize multiple closely spaced sensors (e.g. 36 sensors $1 \mathrm{~cm}$ apart ${ }^{30,31}$ ) have the ability to thoroughly document antral, pyloric, and duodenal contractions (Fig. 1) and have the potential to overcome the technical pitfalls associated with motility catheter movement, e.g. during ambulatory studies.

Performance characteristics Characteristics of normal GI manometry have been established in children ${ }^{32}$ and adults $^{33}$ Reproducibility of different motility findings during prolonged ambulatory recordings performed in the same individuals on two different days is fair to good ( $r$-values ranging between 0.45 and 0.68$).{ }^{34}$ Interlaboratory differences have been noted in the analysis of antroduodenal manometry. ${ }^{35}$ Andersen et al. ${ }^{36}$ analysed the detection of contractions by five observers in antroduodenal manometry and found 60\% overall agreement (range 72-97\% between observer pairs).

In a study assessing interobserver variation for interpretation of antroduodenal manometry in children, ${ }^{37}$ both observers agreed on the differentiation of normal from abnormal motility in $63 \%$ of cases. There was excellent interobserver agreement for quantifying phase III of the MMC and identifying different phases of the MMC. However, agreement for the final diagnosis, which entailed integration of several variables, was weaker. In summary, interobserver agreement for normal vs abnormal antroduodenal motility compares reasonably well with other common diagnostic tests.

While specific patterns are considered to suggest disease $^{38}$ in the absence of a 'gold standard', the sensitivity and specificity of manometry abnormalities for differentiating causes of motility diseases have not been evaluated, except for intestinal obstruction (see above).

Clinical significance and optimal use of intraluminal pressure recordings Intraluminal recordings serve to clarify a clinical diagnosis of abnormal motility or exclude a GI motility disorder, if the gastric emptying test is equivocal. Manometry may suggest unexpected obstruction, low-amplitude contractions (myopathic disorders), disorganized contractions (neuropathic disorder), or unequivocal normality. The latter suggests that motor dysfunction is not a cause of the patient's 
A

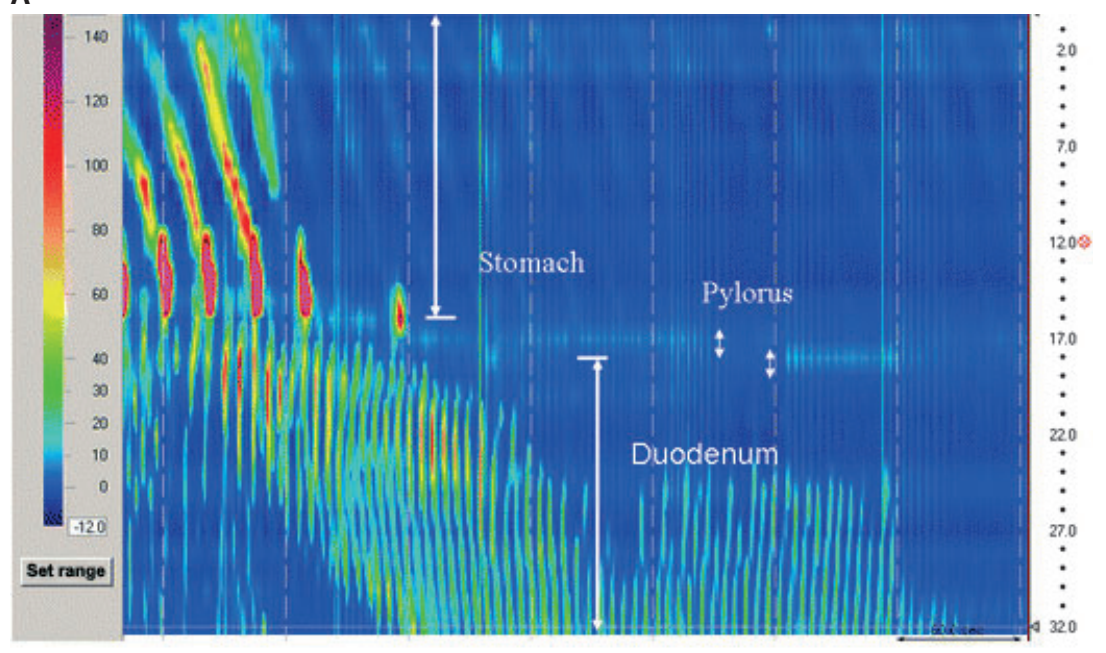

B

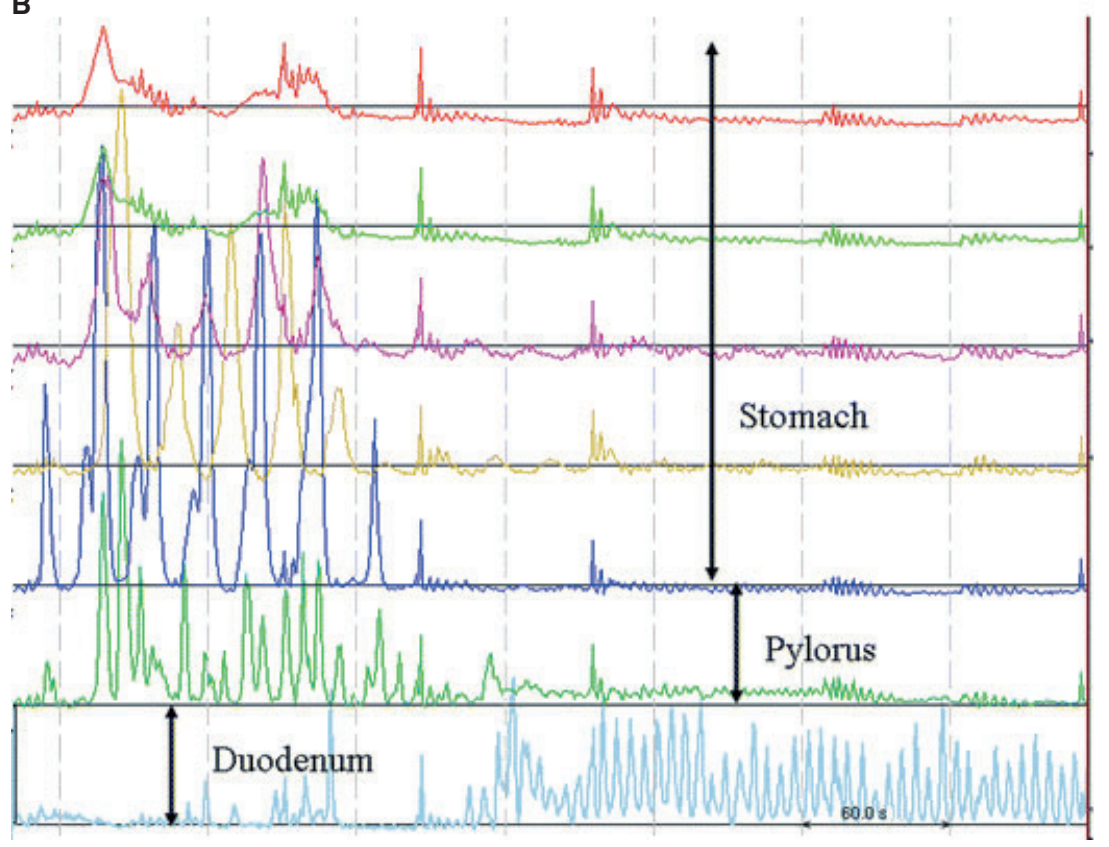

Figure 1 A phase III MMC cycle as shown by isocontour plots (A) and manometry tracings (B). Gastric and pyloric phasic activity cease prior to duodenal activity. The pyloric region remains an area of basal high pressure. Fluoroscopic images correlated with manometric localization of the sphincter, which varied between 17 and $18 \mathrm{~cm}$ from the most proximal transducer. To the left of the isocontour image is a colour code with corresponding pressure. Numbers to the right represent transducer site along the catheter where pressure originates. Data from only 32 of 36 transducers are shown. Reproduced from Friedenberg et $a l^{30}$ symptoms. ${ }^{39}$ An entirely normal study may be the most clinically useful study. In children, the finding of normal gastroduodenal manometry has been reported to be helpful in differentiating a true motility disorder from a polysomatoform disorder in which patients experience daily abdominal pain, illness involving three or more organ systems, an accelerating disease trajectory that may mimic chronic and serious digestive disease and may involve 'falsification', or wilful deception. ${ }^{40}$ Manometric findings (e.g. neuropathy vs myopathy) may direct further investigation (e.g. autonomic tests, full thickness biopsy). While the decision on the optimal site of delivery of enteral nutrition is typically based on a clinical trial (e.g. gastric delivery with assessment of feeding tolerance or gastric residual volumes), some centres rely on manometric findings to assess the extent of disease (localized or not) and to select the route (i.e. gastric, enteric, or parenteral) for nutritional support.

Experience from one centre shows that, in children with unexplained GI symptoms, intestinal dilatation, feeding intolerance or failure to thrive, the absence of MMCs is an indicator of poor response to enteral feeding $^{41}$ or a prokinetic agent. ${ }^{42}$

New technology, such as wireless pressure/pH capsule, provides a more user friendly and less demanding alternative to direct intraluminal pressure measurement. 
Impact of gastroduodenojejunal phasic pressure measurements on patient management The impact of gastroduodenojejunal phasic pressure measurements on the management of patients with presumed small intestinal dysmotility syndromes has not been validated in prospective investigations. In one retrospective review of 109 clinical antroduodenal manometric studies performed over a 7-year period in a tertiary referral centre, ${ }^{43}$ manometric studies resulted in a new therapy in $12.6 \%$, a new diagnosis in $14.9 \%$, referral to another specialist in $8 \%$, and a positive clinical impact in $28.7 \%$ of the patients. In a second retrospective review of 116 patients, abnormal duodenojejunal manometric findings were observed in $40.5 \%$ of the patients, including $48.8 \%$ of those undergoing testing for unexplained abdominal pain, $20.6 \%$ for chronic constipation, $41.7 \%$ for undefined nausea and vomiting, and $62.5 \%$ with presumed chronic intestinal pseudo-obstruction. ${ }^{36}$ Therapeutic decisions were facilitated by the manometric results in $18.9 \%$ of patients, including decisions related to surgical intervention (e.g. colectomy for slow transit constipation) and decisions affecting feeding route (enteral vs parenteral) or choice of prokinetic agents.

Small bowel motility testing is often useful in children with gut failure to clarify the pathogenesis, to optimize clinical management, to determine if intestinal transplantation is needed and, if so, what organs need to be transplanted..$^{44}$ Motor response to the administration of specific drugs during the manometry study may guide medical therapy. ${ }^{42,45}$

\section{Wireless pressure and $\mathrm{pH}$ capsule}

Introduction A wireless pressure and $\mathrm{pH}$ capsule has been recently approved by the US Food and Drug Administration for measuring gastric emptying and whole gut transit time. The capsule also measures phasic motor activity (Fig. 2). The wireless pressure and $\mathrm{pH}$ capsule can accurately measure GI $\mathrm{pH}$ and pressures at normal body temperatures. The capsule transmits sensed data to a data receiver, and data are downloaded via USB connection to a compatible computer for analysis.

Clinical indications In theory, many of the indications for antroduodenojejunal and colonic manometry (Tables 1 and 2) should apply to the wireless pressure and $\mathrm{pH}$ capsule. However, given its size, the capsule should not be used for the manometric diagnosis of mechanical obstruction. Investigations into the clinical utility of wireless pressure and $\mathrm{pH}$ capsule measurements of gastric emptying, small intestinal

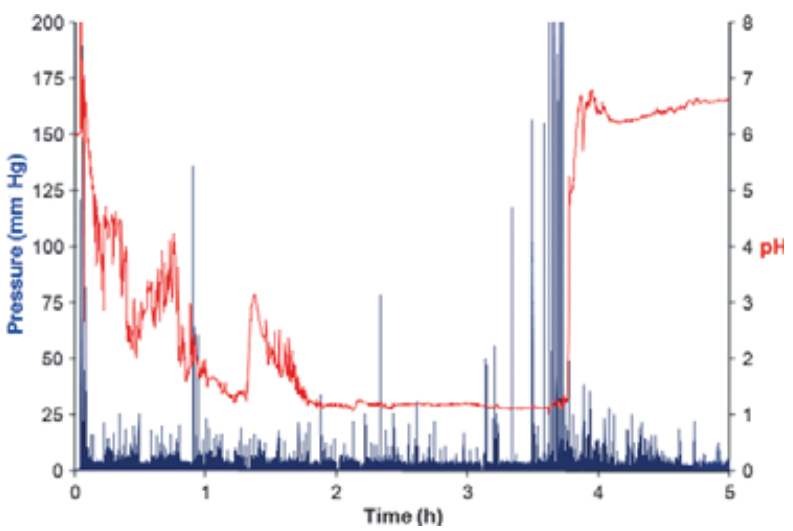

Figure 2 A wireless $\mathrm{pH}$ and motility pill recording. The $\mathrm{pH}$ tracing is shown in red and the pressure tracing is shown in blue. Initially, during the first hour of the gastric recording, there is buffering of the gastric $\mathrm{pH}$ by the ingested meal. Later, the wireless $\mathrm{pH}$ and motility pill records a $\mathrm{pH}$ of about one. At $3 \mathrm{~h} 45 \mathrm{~min}$ after capsule and meal ingestion, there is a rapid rise in the $\mathrm{pH}$, indicating emptying of the pill from the stomach into the duodenum. Prior to emptying of the wireless $\mathrm{pH}$ and motility pill from the stomach, there are high amplitude pressure contractions. Reproduced from Cassilly et al. ${ }^{95}$

Table 2 Indications for intraluminal colonic motility measurements

1 Assess patients with severe constipation, unresponsive to medical therapy, and associated with slow colonic transit and no evidence of an evacuation disorder

2 Confirm chronic megacolon or megarectum in patients whose viscus diameters exceed 10 and $15 \mathrm{~cm}$ respectively

3 Clarify the pathophysiology of persistent symptoms after removal of the aganglionic segment in children with Hirschsprung's disease

4 Evaluate the function of a diverted colon before possible closure of a diverting ostomy

5 Predict the response to antegrade enemas via cecostomy

and colonic transit, and gut contractile activity are ongoing.

Outcomes and endpoints of test Although it is also capable of detecting intraluminal phasic pressure activity, the capsule is only approved to measure gastric emptying.

Capsule gastric emptying time is the time from capsule ingestion to an abrupt rise to a $\mathrm{pH}>6$ as the capsule passes from the acidic antrum to the more neutral duodenum. ${ }^{46}$ However, some gastroparetic patients have reduced intragastric acidity in the late postprandial period, and a $\mathrm{pH}$ increase of $\geq 2$ units rather than the expected $>3$ units may be evident as the capsule migrates from the antrum into the 
duodenum. ${ }^{41}$ In validation studies reported to date, capsule measurements of gastric emptying have been performed with a standardized low-fat test meal; ${ }^{37}$ the capsule is emptied into the duodenum only after complete emptying of the digestible solid meal. Capsule emptying profiles performed under fasting conditions exhibit significant variability, likely secondary to the unpredictable timing of antral MMC activity.

Confounding issues 1 Uncertainty of the exact anatomical location of the capsule precludes reliable characterization of stereotypical patterns such as the MMC. With a single pressure sensor, propagation characteristics of motor activity cannot be defined. Concurrent studies show some correlation between postprandial antral motor activity recorded by a capsule and routine manometry. ${ }^{47}$ Further studies are needed to determine if capsule measurements of pressure provide a reliable postprandial antral motility index.

2 The gastric emptying time for the capsule most probably reflects the gastric emptying of a large nondigestible solid, which is different from the emptying of a digestible solid. ${ }^{48}$ Thus, in healthy subjects, $65 \%$ of individuals emptied the capsule with an antral phase III MMC complex and 35\% with isolated distal antral contractions not associated with phase III activity. ${ }^{39}$ In patients with gastroparesis, profound delay (in some cases $>24 \mathrm{~h}$ ) may be secondary to loss of antral MMC. In validation studies, a second meal was provided $6 \mathrm{~h}$ after capsule ingestion to ensure that diabetics did not develop hypoglycaemia. ${ }^{46}$ If the capsule has not emptied, gastric emptying was censored at $6 \mathrm{~h}$, as in six healthy volunteers and 26 patients with gastroparesis. ${ }^{46}$

Performance characteristics Gastric emptying time by the capsule and concurrent scintigraphy in 77 healthy volunteers and 48 patients with symptoms suggestive of gastroparesis show good correlations with a low-fat test meal $(R=0.73) \cdot{ }^{37,38}$

Clinical significance and optimal use The wireless pressure and $\mathrm{pH}$ capsule has been proposed as an alternate method for identifying delayed gastric emptying in patients with presumed gastroparesis. The 5-h cut-off point for the gastric emptying test provides an optimum balance of sensitivity and specificity $(0.65$ and 0.87 respectively) for diagnosing gastroparesis. ${ }^{46}$ This indicates that the wireless pressure and $\mathrm{pH}$ capsule has sensitivity to identify two-thirds of patients with gastroparesis.
The wireless pressure capsule also measures amplitude of distal antral and duodenojejunal contractions. The role of capsule measurements for identifying myopathic disorders requires formal study. Individual contractions detected by the wireless capsule correlated closely with those observed on manometry in the late postprandial period, prior to capsule evacuation into the duodenum. ${ }^{47}$ The wireless pressure and $\mathrm{pH}$ capsule also measures intragastric acidity. In patients with prolonged gastric emptying of the capsule, loss of gastric acid suggests vagal dysfunction. This occurs more often in diabetic gastroparesis than in idiopathic gastroparetics, and in severely, rather than mildly delayed emptying. ${ }^{49}$

Finally, the wireless pressure and $\mathrm{pH}$ capsule provides an estimate of small bowel and colonic transit, and has the potential to measure amplitude of phasic contractions in the colon (see below).

Impact on patient management The impact of wireless pressure and $\mathrm{pH}$ capsule on the management of patients with presumed upper GI dysmotility has not been studied.

\section{Summary and comparison of measurements of gastrointestinal phasic pressure activity}

Table 3 provides a summary of the comparison of stationary, ambulatory and capsule intraluminal methods for recording gastric and small bowel motility.

\section{Assessment of colonic motor activity}

Introduction After bowel questionnaires, the simplest measurements of colonic motor function include colonic transit by scintigraphy or by radiopaque markers. The latter is widely used to distinguish normal from slow-transit constipation. The wireless pressure and $\mathrm{pH}$ capsule can also assess colonic transit. ${ }^{50}$

As a large diameter viscus, the colon responds to increased intraluminal pressure by a volume change (which defines its compliance) as the viscus stretches. Colonic motor activity is not rhythmic, but is characterized by phasic or brief contractions and tonic or sustained contractions. Tone is measured by barostat; phasic contractions can be measured by manometry or wireless pressure capsule. Stationary laboratorybased studies to assess motility are usually conducted for $6 \mathrm{~h}$, during which compliance, fasting, and 2-h postprandial recordings of contractions and tone are conducted. Ambulatory studies are usually conducted over $24 \mathrm{~h}$ and involve measurements of phasic contractions. 


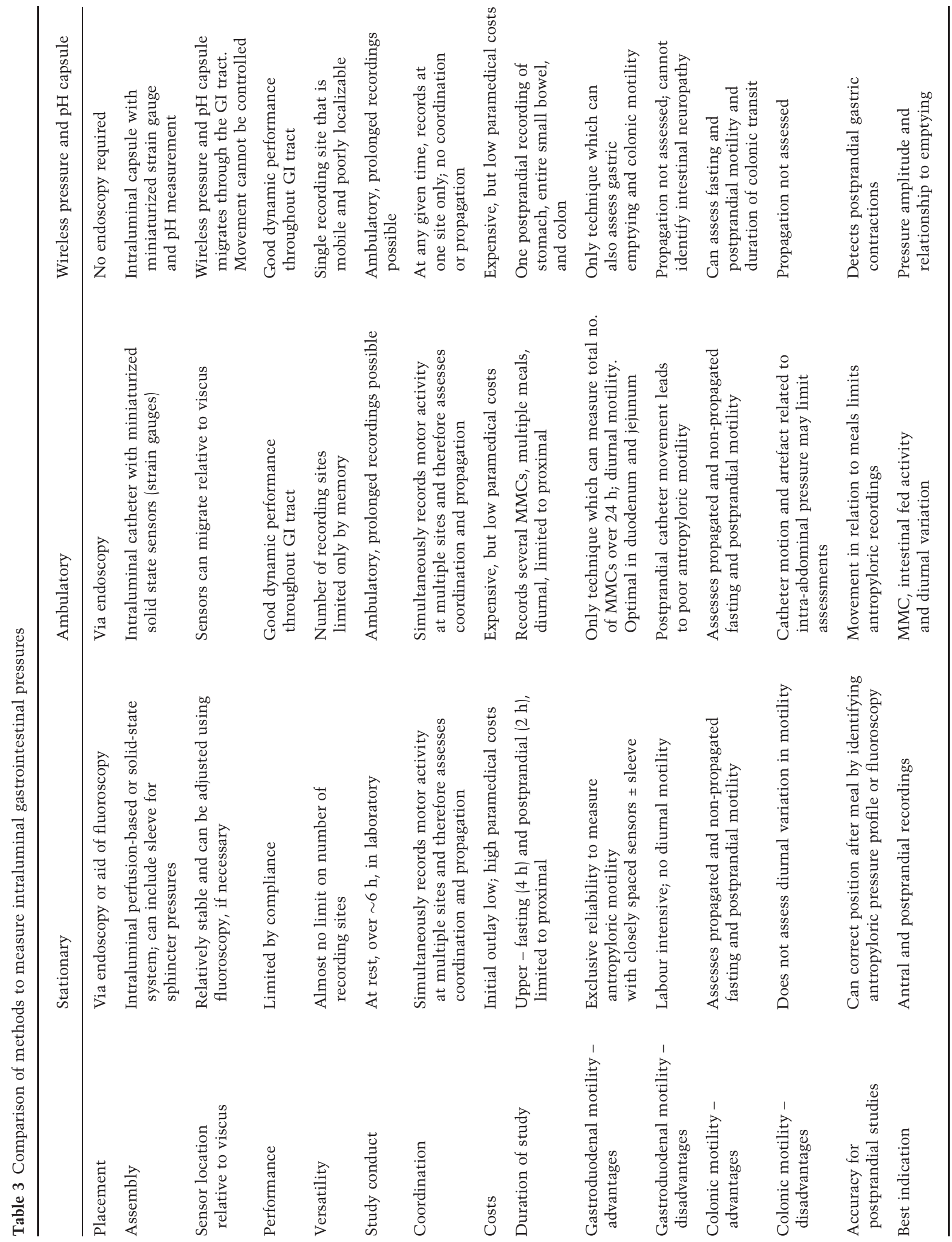


Clinical indications The indications for intraluminal colonic motility tests are shown in Table $2 .{ }^{51-53}$

Outcomes and endpoints of colonic motility tests At least seven different patterns of human colonic phasic pressure activity have been identified ${ }^{54}$ and confirmed by ambulatory study: ${ }^{55}$

1 Isolated pressure waves, which occur randomly without any associated pressure activity for at least $30 \mathrm{~s}$; physiological significance is unclear.

2 Propagating pressure waves, that migrate aborad across $\geq 10 \mathrm{~cm}$ at a velocity $>0.5 \mathrm{~cm} \mathrm{~s}^{-1}$. Propagated contractions propel contents over longer distances than non-propagated contractions. ${ }^{56,57}$

3 High amplitude propagated contractions or pressure sequences (HAPC, $\geq 75 \mathrm{mmHg}$ ) that migrate aborad for $\geq 15 \mathrm{~cm}$; HAPCs occur $\sim 6$ (range 2-24) times daily and may move contents across the colon and precede defecation; ${ }^{54,56,58}$ they occur more frequently in young children and infants. ${ }^{59}$ Other authors ${ }^{60}$ use different parameters to define HAPC: propagation over $24 \mathrm{~cm}$ with a delay of $1-10 \mathrm{~s}$ between peaks seen at sensors $12 \mathrm{~cm}$ apart, and amplitudes of $>50 \mathrm{mmHg}$ absolute pressure at all three sites. Still another group recommends amplitude $>100 \mathrm{mmHg}$ in two sensors and $>80 \mathrm{mmHg}$ in a third sensor. ${ }^{61}$

4 Simultaneous pressure waves occur simultaneously at least $10 \mathrm{~cm}$ apart (onset time $<1 \mathrm{~s}$ ); in paediatric practice, these simultaneous contractions have been associated with neuropathy; however, in adults they are observed in the absence of a neuropathic process.

5 Retrograde pressure waves migrate orad across $\geq 15 \mathrm{~cm}$ with a velocity $>0.5 \mathrm{~cm} \mathrm{~s}^{-1}$.

6 Periodic colonic motor activity or discrete random bursts of phasic and tonic pressure waves with a frequency $\geq 3$ per min and a cycle duration $\geq 3$ per min.

7 Periodic rectal motor activity (PRMA), or discrete rectosigmoid bursts of phasic and tonic pressure waves with a frequency $\geq 3$ waves per min and a cycle duration $\geq 3 / \mathrm{min}$; PRMA occurs predominantly during the night and may serve as a nocturnal break. ${ }^{62,63}$

From a physiological perspective, three patterns of colonic phasic contractions are useful in clinical appraisal:

1 Phasic activity varies diurnally, declining during sleep and increasing upon awakening (Fig. 3). ${ }^{54,64}$

2 Phasic activity increases throughout the colon, starting within a few minutes after the onset of a meal (Fig. 4), and continuing for up to $2 \frac{1}{2} \mathrm{~h}^{65}$ depending on meal composition (fat $>\mathrm{CHO}$ ) and caloric content. ${ }^{66,67}$ Over $500 \mathrm{kcal}$ predictably elic-

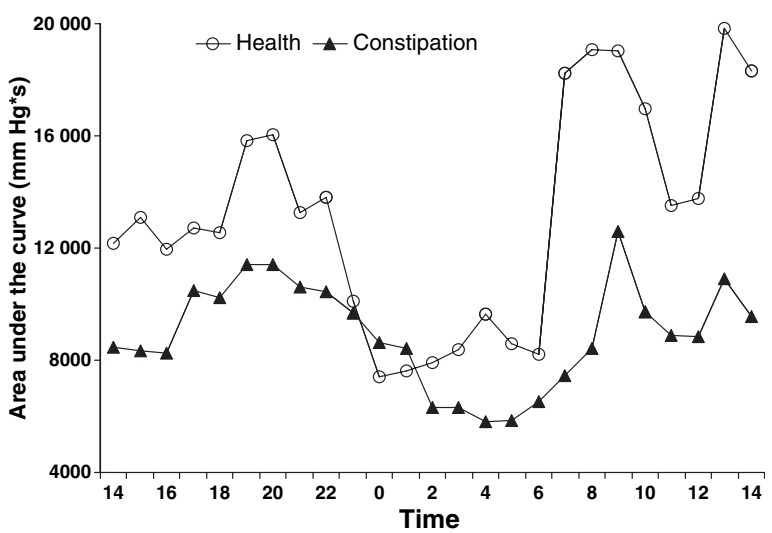

Figure 3 A 24-h profile of the mean area under the curve of colonic pressure waves in healthy controls and in constipated patients. Reproduced from Rao et al. ${ }^{55}$

its this colonic response ${ }^{68}$ neural and hormonal mechanisms are implicated. The absence of HAPCs after the meal suggests a significant colonic motility disorder. There are no published quantitative data of phasic contractility that unequivocally differentiate normal colonic function from colonic inertia. Although wireless capsule studies have identified differences in numbers of colon propagated contractions and colonic motility indices in subsets of patients with constipation compared to healthy controls ${ }^{69}$ the diagnostic significance of these findings is unclear.

3 Colonic instillation of $10-20 \mathrm{mg}$ bisacodyl $\mathrm{l}^{70,71}$ or intravenous neostigmine ${ }^{72}$ induce propagated and HAPCs. ${ }^{70,71}$

Figure 5 shows the evaluation of colonic compliance and tone by a barostat-manometric assembly. Changes in baseline balloon volume reflect changes in colonic tone. A barostat is more accurate than manometry (which acts as a point sensor) for detecting phasic contractions when the colonic diameter exceeds $5.6 \mathrm{~cm}^{73}$ Different segments of the colon present different compliance ${ }^{65}$ reflecting different mechanical properties of active muscle tone (at lower pressures) and passive properties (e.g. connective tissue at higher pressures ${ }^{74}$ ). Increased colonic compliance is identified in chronic megacolon; the significance of an increased colonic compliance in patients with significant slow transit constipation is the subject of ongoing investigation.

Colonic tone in response to a standard meal has been well characterized. This tonic contractile response was more pronounced in the transverse (average increase $24 \%$ over $90 \mathrm{~min}$ ) than the sigmoid colon (average increase $13 \%$ over $90 \mathrm{~min}^{65}$. In the descending colon, the tone increase is median $25 \%$, interquartile range 
A

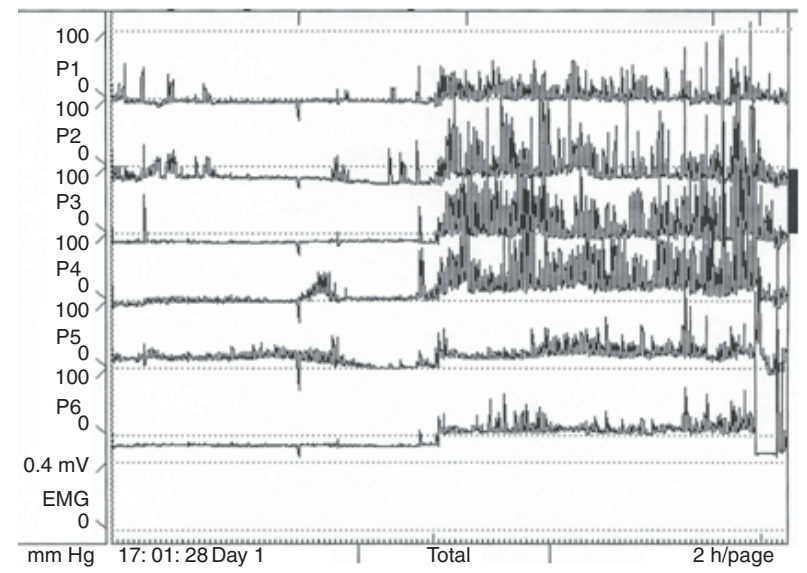

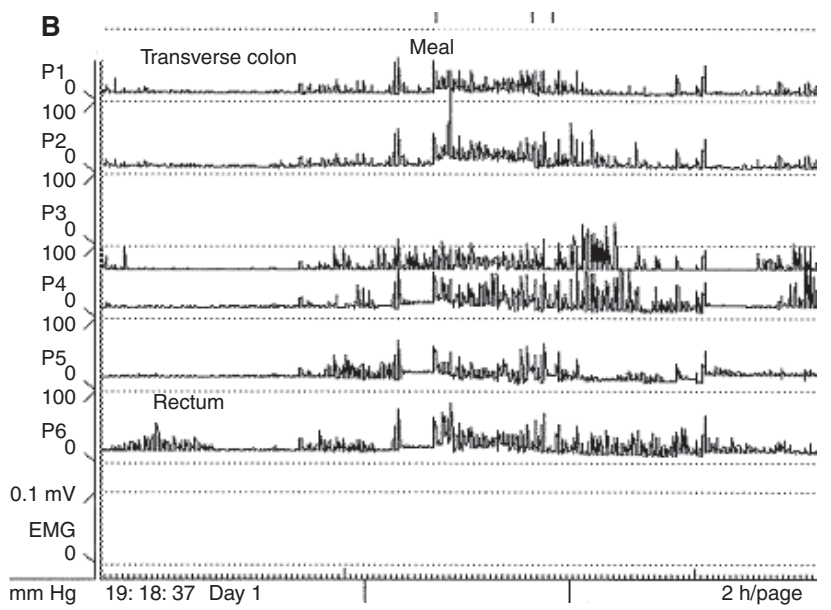

Figure 4 This figure shows an example of the colonic motor activity before and after ingestion of a meal in (A) a healthy subject and (B) a patient with constipation. The healthy subject exhibits a sustained increase in colonic motility immediately after eating in all channels, whereas the patient shows a markedly attenuated, short-lived, meal-induced motor response. Reproduced from Rao et $a 1 .{ }^{55}$

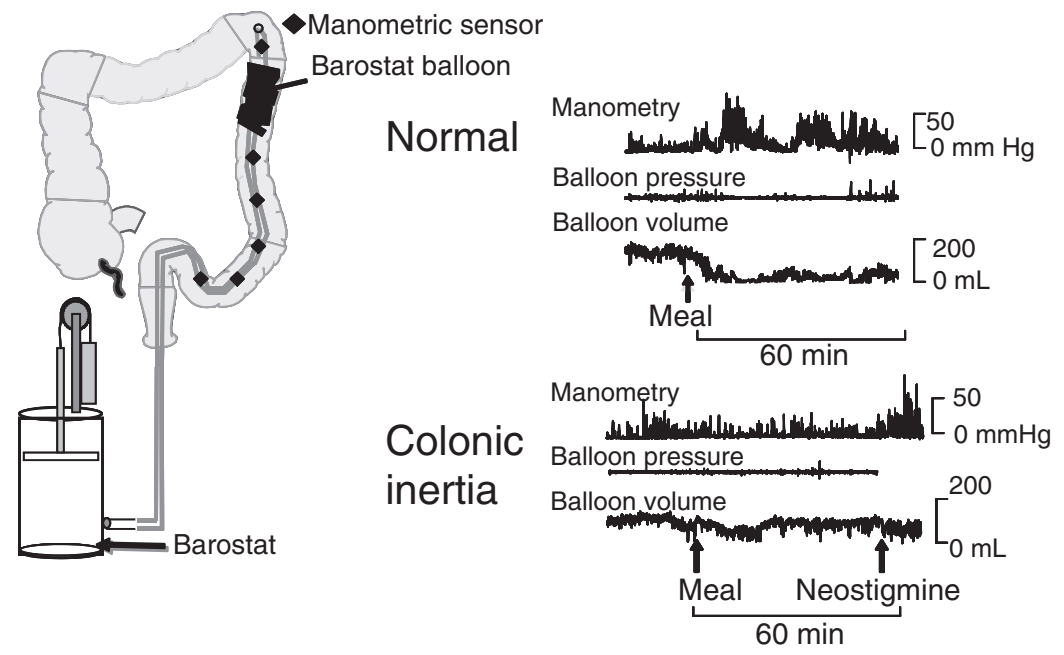

Figure 5 Evaluation of colonic motor functions by a barostat-manometric assembly. Left panel shows a barostat-manometric assembly, comprising a polyethylene balloon (10 cm long) and water perfused manometric sensors connected by polyethylene tubing to a barostat. Colonic contractile responses to a meal and pharmacological stimuli are assessed by inflating the balloon so that it is opposed to the colonic mucosa. Under these circumstances, a normal postprandial colonic contractile response is accompanied by displacement of air from the balloon to the cylinder and balloon volume declines (right upper panel). Colonic inertia is defined by impaired contractile responses to a meal and to neostigmine (right lower panel).

$21-45 \%$, compared to fasting. ${ }^{75}$ Thus, a $<15 \%$ increase in tone after the meal suggests a significant colonic motility disorder.

Analyses and measurements of colonic motility may be qualitative or quantitative.

1 Qualitative: Manual inspection or computerized algorithms identify common patterns such as propagated contractions, retrograde contractions, PRMA and HAPCs. Their number, frequency and diurnal variation are noted.
2 Quantitative: Phasic pressure activity, summarized as area under the curve or a motility index, i.e. $\left[\log _{\mathrm{e}}\right.$ (sum of amplitudes ${ }^{\star}$ number of contractions +1 )], is compared before and after events such as awakening and meals (Fig. 4). Colonic tone is estimated as balloon volume at operating pressure under fasting conditions (e.g. for $30 \mathrm{~min}$ ), after a meal (e.g. for $60 \mathrm{~min}$ ), and after a pharmacological stimulus (e.g. after neostigmine or bisacodyl for $30 \mathrm{~min})$. Colonic pressure-volume relationships can be summarized 
by a power exponential or simpler linear interpolation method. ${ }^{74,76,77}$

Confounding issues Many of the confounding issues discussed under intraluminal gastroduodenojejunal manometry also apply to colonic manometry. The techniques are only partially standardized. The following factors may limit interpretation of colonic manometry and barostat assessments.

1 Artefacts caused by cough, movement, or straining are associated with simultaneous pressure activity recorded by multiple sensors; the profile is easily differentiated from colonic motor events. Stationary studies also incorporate a pneumobelt, which records artefacts.

2 The pathophysiological mechanism (e.g. neuropathy, myopathy and/or dysfunction of interstitial cells of Cajal) responsible for symptoms cannot be identified from the motor patterns. Moreover, pelvic floor dysfunction is associated with colonic motor dysfunction. ${ }^{78,79}$ While major disturbances (e.g. colonic inertia) reflect severe dysfunctions, the significance of minor abnormalities (i.e. a subtle reduction in the colonic contractile response to a meal) is unclear.

3 Phasic responses to a meal may be normal in patients with megacolon; however, tone and compliance are abnormal and are detected by combined barostatmanometry.

4 Differences in the interpretation of motility based on the location of the probe; for example, HAPCs are more common in the right and transverse than the left colon.

5 The values of contractile amplitudes measured by water perfused and solid-state manometry may differ, which may affect the measurements of motility indices and HAPCs. An adequate healthy control data set is essential for interpreting an abnormal test.

6 Although wireless capsule can measure colonic pressures as it traverses the colon, it does not provide information on colonic motor patterns, such as HAPC, PRMA, or colonic tone, and it may not discriminate neuropathic and myopathic patterns in the colon.

Performance characteristics Colonic tone and phasic contractions have been investigated over the past 2 decades, and the interindividual coefficients of variation are $24 \%$ for postprandial colonic motility index and $47 \%$ for postprandial colonic tone (Camilleri, unpublished observation). No such data are available for the wireless capsule.

Clinical significance and optimal use Chronic constipation associated with severe colonic motor dysfunc- tion $^{80,81}$ is characterized by absence of HAPCs over $24 \mathrm{~h}$, reduced antegrade propagating motor activity, ${ }^{82}$ reduced (i.e. $<15 \%$ ) postprandial increase in colonic tone ${ }^{83}$ reduced HAPCs in response to pharmacological stimuli (e.g. bisacodyl, ${ }^{84}$ neostigmine ${ }^{85}$ ), or reduced colonic compliance. Some centres subclassify such patients as colonic inertia. ${ }^{86}$ In those centres that use colonic motility test, a diagnosis of colonic inertia is required before offering the patient subtotal colectomy with ileorectostomy for severe constipation. The rationale for this approach is supported by observations which suggest that colonic transit is an imperfect surrogate marker of colonic motor dysfunction as assessed by intraluminal testing. Thus, a subset of patients with slow transit constipation and normal defecation has normal colonic motor functions assessed by barostat-manometry. ${ }^{87}$

In practice, many centres use multiple /variable number) failed therapeutic trials as the indication for referral for colectomy in those with documented slow colonic transit and normal evacuation. Some centres have indicated that they would do colon manometry if there was reimbursement for such procedures.

In contrast to constipation, a subset of patients with diarrhoea, particularly in association with autonomic neuropathy, has more frequent HAPCs during the day and/or after a meal. ${ }^{64,67,83,88-92}$

Impact on patient management Paediatric practice: Colonic motility testing has impacted diagnosis and treatment of constipation in children. Studies performed in large motility centres using both the antegrade and the retrograde approach have suggested that colonic manometry can be used to:

1 Select medical and surgical treatment when conventional medical and behavioural treatments have failed. ${ }^{93,94}$

2 Clarify the pathophysiology of persistent symptoms after removal of the aganglionic segment in children with Hirschsprung's disease. ${ }^{51}$

3 Evaluate the function of a diverted colon before possible closure of a diverting stoma. ${ }^{52}$

4 Predict the response to antegrade enemas via cecostomy. ${ }^{53}$

Adult practice: The impact of colonic motility testing to guide the management of chronic constipation in adults is documented in one study of 19 patients with severe slow transit constipation: seven of 10 patients with features of a neuropathy underwent colectomy while the remaining 12 patients (five had myopathy and four had normal manometry) were managed with medical measures. At 1 year, symptoms resolved in six of seven patients who underwent 
Table 4 Comparison of techniques for assessing intraluminal colonic motor activity

\begin{tabular}{|c|c|c|c|c|}
\hline & $\begin{array}{l}\text { Phasic } \\
\text { activity }\end{array}$ & $\begin{array}{l}\text { Propagated } \\
\text { contractions }\end{array}$ & $\begin{array}{l}\text { Tone and } \\
\text { compliance }\end{array}$ & $\begin{array}{l}\text { Gastric and } \\
\text { small } \\
\text { intestinal } \\
\text { activity }\end{array}$ \\
\hline Manometry & ++ & ++ & - & - \\
\hline Barostat & ++ & - & ++ & - \\
\hline Capsule & ++ & - & - & + \\
\hline
\end{tabular}

++Definite, +partial assessment, -does not assess.

colectomy and improved by an average of $50 \%$ in the five patients with myopathy. ${ }^{55}$ The impact of the two approaches (colonic motility test to identify significant colonic dysmotility vs multiple failed therapeutic trials) on outcomes to surgery and patient preference has not been formally compared.

Summary A comparison of techniques for assessing intraluminal colonic motor activity is shown in Table 4. Measurement of colonic motility and tone is established as a valid clinical tool to facilitate the management of significant motility disorders in adult and paediatric practice.

\section{CONCLUSION}

Intraluminal measurement of gastric and small bowel and colonic phasic pressure has been used in clinical practice for almost 3 decades. Although these studies were initially restricted to specialized motility laboratories and stationary studies, the availability of standardized equipment and techniques has enhanced these measurements, which now include ambulatory studies at all levels, and measurements of compliance, tone and response to pharmacological agents in the colon. These advances have made the measurements more widely available. This consensus document has been written to provide a critical review of the indications, strengths, performance characteristics, optimal use, impact and pitfalls of the different techniques to measure intraluminal pressures in the proximal gut and in the colon. Novel approaches, including wireless capsule measurements of $\mathrm{pH}$ and motility, may facilitate the measurements of intraluminal pressures, though further validation studies are needed.

\section{ACKNOWLEDGMENT}

We thank Mrs Cindy Stanislav for excellent secretarial assistance.

\section{REFERENCES}

1 Camilleri M, Hasler WL, Parkman HP, Quigley EM, Soffer E. Measurement of gastrointestinal motility in the GI laboratory. Gastroenterology 1998; 115: 74762.

2 Wilson P, Perdikis G, Hinder RA, Redmond EJ, Anselmino M, Quigley EM. Prolonged ambulatory antroduodenal manometry in humans. Am I Gastroenterol 1994; 89: 1489-95.

3 von Schönfeld J, Evans DF, Renzing K, Castillo FD, Wingate DL. Human small bowel motor activity in response to liquid meals of different caloric value and different chemical composition. Dig Dis Sci 1998; 43: 265-72.

4 Camilleri M, Brown ML, Malagelada JR. Relationship between impaired gastric emptying and abnormal gastrointestinal motility. Gastroenterology 1986; 91: 94-9.

5 Thumshirn M, Bruninga K, Camilleri M. Simplifying the evaluation of postprandial antral motor function in patients with suspected gastroparesis. Am J Gastroenterol 1997; 92: 1496-500.

6 Frank JW, Sarr MG, Camilleri M. Use of gastroduodenal manometry to differentiate mechanical and functional intestinal obstruction: an analysis of clinical outcome. Am J Gastroenterol 1994; 89: 339-44.

7 Greydanus MP, Camilleri M. Abnormal postcibal antral and small bowel motility due to neuropathy or myopathy in systemic sclerosis. Gastroenterology 1989; 96: 110-5.

8 Prather CM, Camilleri M, Thomforde GM, Forstrom LA, Zinsmeister AR. Gastric axial forces in experimentally delayed and accelerated gastric emptying. Am I Physiol 1993; 264: G928-34.

9 Weston S, Thumshirn M, Wiste J, Camilleri M. Clinical and upper gastrointestinal motility features in systemic sclerosis and related disorders. Am I Gastroenterol 1998; 93: 1085-9.

10 Fich A, Neri M, Camilleri M, Kelly KA, Phillips SF. Stasis syndromes following gastric surgery: clinical and motility features of 60 symptomatic patients. I Clin Gastroenterol 1990; 12: 505-12.

11 Samsom M, Jebbink RJ, Akkermans LM, van BergeHenegouwen GP, Smout AJ. Abnormalities of antroduodenal motility in type I diabetes. Diabetes Care 1996; 19: 21-7.

12 Balaji NS, Crookes PF, Banki F, Hagen JA, Ardill JE, DeMeester TR. A safe and noninvasive test for vagal integrity revisited. Arch Surg 2002; 137: 954-8.

13 Camilleri M, Carbone LD, Schuffler MD. Familial enteric neuropathy with pseudo-obstruction. Dig Dis Sci 1991; 36: 1168-71.

14 Lindberg G, Iwarzon M, Veress B. Small bowel motility patterns in patients with chronic intestinal pseudoobstruction. Gastroenterology 1994; 106: A532.

15 Bhaskar SK, Abell TL, Dean P, Voeller G, Familoni BO. Comparison of intraoperative small bowel electrophysiology and full thickness biopsy. Gastroenterology 1996; 110: A634.

16 De Giorgio R, Sarnelli G, Corinaldesi R, Stanghellini V. Advances in our understanding of the pathology of chronic intestinal pseudo-obstruction. Gut 2004; 53: 1549-52.

17 Camilleri M, Malagelada JR. Abnormal intestinal motility in diabetics with the gastroparesis syndrome. Eur I Clin Invest 1984; 14: 420-7. 
18 Camilleri M, Malagelada JR, Stanghellini V, Fealey RD, Sheps SG. Gastrointestinal motility disturbances in patients with orthostatic hypotension. Gastroenterology 1985; 88: 1852-9.

19 Wood JR, Camilleri M, Low PA, Malagelada JR. Brainstem tumor presenting as an upper gut motility disorder. Gastroenterology 1985; 89: 1411-4.

20 Stanghellini V, Camilleri M, Malagelada JR. Chronic idiopathic intestinal pseudo-obstruction: clinical and intestinal manometric findings. Gut 1987; 28: 5-12.

21 Stanghellini V, Cogliandro RF, De Giorgio R et al. Natural history of chronic idiopathic intestinal pseudo-obstruction in adults: a single center study. Clin Gastroenterol Hepatol 2005; 3: 449-58.

22 Stanghellini V, Cogliandro RF, de Giorgio R, Barbara G, Salvioli B, Corinaldesi R. Chronic intestinal pseudoobstruction: manifestations, natural history and management. Neurogastroenterol Motil 2007; 19: 440-52.

23 Amarnath RP, Abell TL, Malagelada J-R. The rumination syndrome in adults. A characteristic manometric pattern. Ann Intern Med 1986; 105: 513-8.

24 Chial HJ, Camilleri M, Williams DE, Litzinger K, Perrault J. Rumination syndrome in children and adolescents: diagnosis, treatment, and prognosis. Pediatrics 2003; 111: 158-62.

25 O'Brien $\mathrm{MD}$, Bruce $\mathrm{BK}$, Camilleri $\mathrm{M}$. The rumination syndrome: clinical features rather than manometric diagnosis. Gastroenterology 1995; 108: 1024-9.

26 Abell TL, Malagelada J-R, Lucas AR et al. Gastric electromechanical and neurohormonal function in anorexia nervosa. Gastroenterology 1987; 93: 958-65.

27 Kamal N, Chami T, Andersen A, Rosell FA, Schuster MM, Whitehead WE. Delayed gastrointestinal transit times in anorexia nervosa and bulimia nervosa. Gastroenterology 1991; 101: 1320-4.

28 Reynolds JC, Ouyang A, Lee CA, Baker L, Sunshine AG, Cohen S. Chronic severe constipation. Prospective motility studies in 25 consecutive patients. Gastroenterology 1987; 92: 414-20.

29 Chun AB, Sokol MS, Kaye WH, Hutson WR, Wald A. Colonic and anorectal function in constipated patients with anorexia nervosa. Am I Gastroenterol 1997; 92: 187983.

30 Friedenberg FK, Desipio J, Korimilli A et al. Tonic and phasic pyloric activity in response to CCK-octapeptide. Dig Dis Sci 2008; 53: 905-11.

31 Desipio J, Friedenberg FK, Korimilli A, Richter JE, Parkman HP, Fisher RS. High-resolution solid-state manometry of the antropyloroduodenal region. Neurogastroenterol Motil 2007; 19: 188-95.

32 Uc A, Hoon A, Di Lorenzo C, Hyman PE. Antroduodenal manometry in children with no upper gastrointestinal symptoms. Scand J Gastroenterol 1997; 32: 681-5.

33 Bortolotti M, Annese V, Coccia G. Twenty-four hour ambulatory antroduodenal manometry in normal subjects (co-operative study). Neurogastroenterol Motil 2000; 12: 231-8.

34 Penning C, Gielkens HA, Hemelaar M, Lamers CB, Masclee AA. Reproducibility of antroduodenal motility during prolonged ambulatory recording. Neurogastroenterol Motil 2001; 13: 133-41.

35 Bjornsson E, Castedal M, Abrahamsson $\mathrm{H}$. Interlaboratory differences in method for analysis of manometry explain discrepancies in studies of duodenal phase III peristalsis. Neurogastroenterol Motil 2003; 15: 331-3.

36 Andersen MB, Stodkilde-Jorgensen H, Kraglund K, Djurhuus JC, Rosenfalck A. Consistency in manual scoring analysis of gastrointestinal pressure recordings. Scand $J$ Gastroenterol 1989; 24: 321-8.

37 Connor FL, Hyman PE, Faure $\mathrm{C}$ et al. Interobserver variability in antroduodenal manometry. Neurogastroenterol Motil 2008 doi: 10.1111/j.1365-2982.2008.01159.x (Epub ahead of print).

38 Tomomasa T, DiLorenzo C, Morikawa A, Uc A, Hyman PE. Analysis of fasting antroduodenal manometry in children. Dig Dis Sci 1996; 41: 2195-203.

39 Cucchiara S, Borrelli O, Salvia G et al. A normal gastrointestinal motility excludes chronic intestinal pseudo-obstruction in children. Dig Dis Sci 2000; 45: 258-64.

40 Hyman PE, Bursch B, Beck D, DiLorenzo C, Zeltzer LK. Discriminating pediatric condition falsification from chronic intestinal pseudo-obstruction in toddlers. Child Maltreat 2002; 7: 132-7.

41 Di Lorenzo C, Flores AF, Buie T, Hyman PE. Intestinal motility and jejunal feeding in children with chronic intestinal pseudo-obstruction. Gastroenterology 1995; 108: 1379-85.

42 Hyman PE, Di Lorenzo C, McAdams L, Flores AF, Tomomasa T, Garvey TQ. Predicting the clinical response to cisapride in children with chronic intestinal pseudoobstruction. Am J Gastroenterol 1993; 88: 832-6.

43 Verhagen MA, Samsom M, Jebbink RJ, Smout AJ. Clinical relevance of antroduodenal manometry. Eur I Gastroenterol Hepatol 1999; 11: 523-8.

44 Sigurdsson L, Reyes J, Kocoshis SA et al. Intestinal transplantation in children with chronic intestinal pseudoobstruction. Gut 1999; 45: 570-4.

45 Verne GN, Eaker EY, Hardy E, Sninsky CA. Effect of octreotide and erythromycin on idiopathic and scleroderma-associated intestinal pseudo-obstruction. Dig Dis Sci 1995; 40: 1892-901.

46 Kuo B, McCallum RW, Koch KL et al. Comparison of gastric emptying of a nondigestible capsule to a radiolabelled meal in healthy and gastroparetic subjects. Aliment Pharmacol Ther 2008; 27: 186-96.

47 Hasler W, Knight L, Cassilly D et al. Characterization of postprandial gastric motor activity in healthy subjects using a wireless pressure-sensing capsule: correlation with fed pattern on antroduodenal manometry. Neurogastroenterol Motil 2008; 20(Suppl. 1): 86.

48 Hinder RA, Kelly KA. Canine gastric emptying of solids and liquids. Am J Physiol 1977; 233: E335-40.

49 Hasler WL, Coleski R, Chey WD et al. Differences in intragastric $\mathrm{pH}$ in diabetic versus idiopathic gastroparesis: relation to degree of gastric retention. Am J Physiol 2008; 294: G1384-91.

50 Rao SSC, Kuo B, Chey W et al. Investigation of wireless capsule (Smartpill) for colonic transit: a comparative study with radioopaque markers in health and constipation. Am J Gastroenterol 2007; 102: S512.

51 Di Lorenzo C, Solzi GF, Flores AF, Schwankovsky L, Hyman PE. Colonic motility after surgery for Hirschsprung's disease. Am J Gastroenterol 2000; 95: 1759-64.

52 Villarreal J, Sood M, Zangen $\mathrm{T}$ et al. Colonic diversion for intractable constipation in children: colonic manometry 
helps guide clinical decisions. I Pediatr Gastroenterol Nutr 2001; 33: 588-91.

53 van den Berg MM, Hogan M, Caniano DA, Di Lorenzo C, Benninga MA, Mousa HM. Colonic manometry as predictor of cecostomy success in children with defecation disorders. J Pediatr Surg 2006; 41: 730-6.

54 Rao SS, Sadeghi P, Beaty J, Kavlock R, Ackerson K. Ambulatory 24-h colonic manometry in healthy humans. Am I Physiol 2001; 280: G629-39.

55 Rao SS, Sadeghi P, Beaty J, Kavlock R. Ambulatory 24-hour colonic manometry in slow-transit constipation. Am J Gastroenterol 2004; 99: 2405-16.

56 Cook IJ, Furukawa Y, Panagopoulos V, Collins PJ, Dent J. Relationships between spatial patterns of colonic pressure and individual movements of content. Am I Physiol 2000; 278: G329-41.

57 Steadman C, Phillips S, Camilleri M, Haddad A, Hanson R. Variation in muscle tone in the human colon. Gastroenterology 1991; 101: 373-81.

58 Bampton PA, Dinning PG, Kennedy ML, Lubowski DZ, deCarle D, Cook IJ. Spatial and temporal organization of pressure patterns throughout the unprepared colon during spontaneous defecation. Am I Gastroenterol 2000; 95: 1027-35

59 Di Lorenzo C, Flores AF, Hyman PE. Age-related changes in colon motility. J Pediatr 1995; 127: 593-6.

60 Bassotti G, Gaburri M. Manometric investigation of highamplitude propagated contractile activity of the human colon. Am I Physiol 1988; 255: G660-4.

61 De Schryver AMP, Samsom M, Smout AJP. In search of objective manometric criteria for colonic high-amplitude propagated pressure waves. Neurogastroenterol Motil 2002; 14: 375-81.

62 Rao SS, Welcher K. Periodic rectal motor activity: the intrinsic colonic gatekeeper? Am J Gastroenterol 1996; 91: 890-7.

63 Prior A, Fearn UJ, Read NW. Intermittent rectal motor activity: a rectal motor complex? Gut 1991; 32: 1360-3.

64 Narducci F, Bassotti G, Gaburri M, Morelli A. Twentyfour hour manometric recording of colonic motor activity in healthy man. Gut 1987; 28: 17-25.

65 Ford MJ, Camilleri M, Wiste JA, Hanson RB. Differences in colonic tone and phasic responses to a meal in the transverse and sigmoid human colon. Gut 1995; 37: 264-9.

66 Rao SS, Kavelock R, Beaty J, Ackerson K, Stumbo P. Effects of fat and carbohydrate meals on colonic motor response. Gut 2000; 46: 205-11.

67 Bazzocchi G, Ellis J, Villanueva-Meyer J et al. Postprandial colonic transit and motor activity in chronic constipation. Gastroenterology 1990; 98: 686-93.

68 Snape WJ Jr, Wright SH, Battle WM, Cohen S. The gastrocolic response: evidence for a neural mechanism. Gastroenterology 1979; 77: 1235-40.

69 Hasler WL, Saad RJ, Rao SS et al. Heightened motor activity measured by a wireless capsule in unprepared colons of patients with complaints of constipation: relation to colon transit and IBS. Gastroenterology 2008; 134: W1312.

70 Bassotti G, Gaburri M, Imbimbo BP, Morelli A, Whitehead WE. Distension-stimulated propagated contractions in human colon. Dig Dis Sci 1994; 39: 1955-60.

71 Bassotti G, Chiarioni G, Germani U, Battaglia E, Vantini I, Morelli A. Endoluminal instillation of bisacodyl in patients with severe (slow transit type) constipation is useful to test residual colonic propulsive activity. Digestion 1999; 60: 69-73.

72 Law NM, Bharucha AE, Undale AS, Zinsmeister AR. Cholinergic stimulation enhances colonic motor activity, transit, and sensation in humans. Am J Physiol 2001; 281: G1228-37.

73 von der Ohe M, Hanson RB, Camilleri M. Comparison of simultaneous recordings of human colonic contractions by manometry and a barostat. Neurogastroenterol Motil 1994; 6: 213-622.

74 Bharucha AE, Hubmayr RD, Ferber IJ, Zinsmeister AR. Viscoelastic properties of the human colon. Am I Physiol 2001; 281: G459-66.

75 von der Ohe MR, Hanson RB, Camilleri M. Serotonergic mediation of postprandial colonic tonic and phasic responses in humans. Gut 1994; 35: 536-41.

76 Bharucha AE, Camilleri M, Zinsmeister AR, Hanson RB. Adrenergic modulation of human colonic motor and sensory function. Am J Physiol 1997; 273: G997-1006.

77 Floyd BN, Camilleri M, Andresen V, Esfandyari T, Busciglio I, Zinsmeister AR. Comparison of mathematical methods for calculating colonic compliance in humans: power exponential, computer-based and manual linear interpolation models. Neurogastroenterol Motil 2008; 20: 330-5.

78 Mollen RM, Salvioli B, Camilleri M et al. The effects of biofeedback on rectal sensation and distal colonic motility in patients with disorders of rectal evacuation: evidence of an inhibitory rectocolonic reflex in humans. Am I Gastroenterol 1999; 94: 751-6.

79 Law N-M, Bharucha AE, Zinsmeister AR. Rectal and colonic distention-elicit viscerovisceral reflexes in humans. Am J Physiol 2002; 283: G384-9.

80 Preston DM, Lennard-Jones JE. Severe chronic constipation of young women: 'idiopathic slow transit constipation'. Gut 1986; 27: 41-8.

81 Di Lorenzo C, Flores AF, Reddy SN, Snape WJ Jr, Bazzocchi G, Hyman PE. Colonic manometry in children with chronic intestinal pseudo-obstruction. Gut 1993; 34: 803-7.

82 King SK, Catto-Smith AG, Stanton MP et al. 24-hour colonic manometry in pediatric slow transit constipation shows significant reductions in antegrade propagation. Am J Gastroenterol 2008; 103: 2083-91.

83 O'Brien MD, Camilleri M, von der Ohe MR et al. Motility and tone of the left colon in constipation: a role in clinical practice? Am I Gastroenterol 1996; 91: 2532-8.

84 Preston DM, Lennard-Jones JE. Pelvic motility and response to intraluminal bisacodyl in slow-transit constipation. Dig Dis Sci 1985; 30: 289-94.

85 Grotz RL, Pemberton JH, Levin KE, Bell AM, Hanson RB. Rectal wall contractility in healthy subjects and in patients with chronic severe constipation. Ann Surg 1993; 218: 761-8.

86 Lembo A, Camilleri M. Chronic constipation. $N$ Engl I Med 2003; 349: 1360-8.

87 Ravi K, Bharucha AE, Camilleri M, Rhoten D, Zinsmeister AR. Relationship between colonic motor functions and transit in constipation. Gastroenterology 2008; 134: A677.

88 Choi MG, Camilleri M, O'Brien MD, Kammer PP, Hanson $\mathrm{RB}$. A pilot study of motility and tone of the left colon in 
patients with diarrhea due to functional disorders and dysautonomia. Am J Gastroenterol 1997; 92: 297-302.

89 Bazzocchi G, Ellis J, Villanueva-Meyer J, Reddy SN, Mena I, Snape WJ Jr. Effect of eating on colonic motility and transit in patients with functional diarrhea. Simultaneous scintigraphic and manometric evaluations. Gastroenterology 1991; 101: 1298-306.

90 Chey WY, Jin HO, Lee MH, Sun SW, Lee KY. Colonic motility abnormality in patients with irritable bowel syndrome exhibiting abdominal pain and diarrhea. Am I Gastroenterol 2001; 96: 1499-506.

91 Dinning PG, Bampton PA, Andre J et al. Abnormal predefecatory colonic motor patterns define constipation in obstructed defecation. Gastroenterology 2004; 127: 4956.

92 Dinning PG, Szczesniak MM, Cook IJ. Proximal colonic propagating pressure waves sequences and their relationship with movements of content in the proximal human colon. Neurogastroenterol Motil 2008; 20: 51220.

93 Pensabene L, Youssef NN, Griffiths JM, Di Lorenzo C. Colonic manometry in children with defecatory disorders. Role in diagnosis and management. Am J Gastroenterol 2003; 98: 1052-7.

94 Martin MJ, Steele SR, Mullenix PS, Noel JM, Weichmann D, Azarow KS. A pilot study using total colonic manometry in the surgical evaluation of pediatric functional colonic obstruction. J Pediatr Surg 2004; 39: 352-9.

95 Cassilly D, Kantor S, Knight LC, Maurer AH, Fisher RS, Semler J, Parkman HP. Gastric emptying of a non-digestible solid: assessment with simultaneous Smart Pill pH and pressure capsule, antroduodenal manometry, gastric emptying scintigraphy. Neurogastroenterol Motil 2008; 20: 311-9. 